\section{Cronología de las prácticas de Ordenamiento, conflicto e intratabilidad: el caso de la Reserva del Bosque Oriental de Bogotá*}

Chronology of Land Planning, Conflict and Intractability: The Case of East Forest Reserve Bogota

Cronologia das práticas de Ordenamento, conflito e intratabilidade: o caso da Reserva do Bosque Oriental de Bogotá

Humberto Rojas-Pinilla**

Artículo recibido: 12 de abril de 2016

Artículo aprobado: 12 de septiembre 2016

Doi: http://dx.doi.org/10.12804/revistas.urosario.edu.co/territorios/a.4777

Para citar este artículo:

Rojas-Pinilla, H. (2017). Cronología de las prácticas de Ordenamiento, conflicto e intratabilidad: el caso de la Reserva del Bosque Oriental de Bogotá. Territorios (36), 111-137. Doi: http://dx.doi.org/10.12804/ revistas.urosario.edu.co/territorios/a.4777

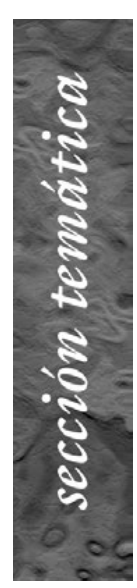

* Este artículo corresponde a un capitulo modificado de la tesis doctoral titulada "Intratabilidad, poder y territorio. El caso del conflicto ambiental de San Isidro Patios, Bogotá 1976-2014”, Dirigida por la Dra. Donny Meertens, codirigida por el Dr. César Ortiz y financiada con recursos de la Vicerrectoría de Investigación de la Pontificia Universidad Javeriana de Bogotá.

** Profesor Asociado, Pontificia Universidad Javeriana. Facultad de Estudios Ambientalesy Rurales, Departamento de Desarrollo Rural y Regional. Correo electrónico: humberto.rojas@javeriana.edu. co. ORCID: http://orcid. org/0000-0002-8957-1787 
Palabras clave

Intratabilidad,

Habitus, Cronologia,

Conflicto por recursos

naturales, Prácticas de ordenamiento y gestión de la población.

Keywords

VIntractability, Habitus, Chronology, conflict over natural resources, land planning practices and population management.

Palavras-chave

Intratabilidade, Habitus, Cronologia, Conflito por recursos naturais, práticas de ordenamento $e$ gestão da população.

\section{territarias 36}

\section{RESUMEN}

Los principales rasgos de intratabilidad en los conflictos son: la larga duración, recurrencia y fracaso de los intentos de transformación, involucrar al Estado, la lucha por necesidades fundamentales, así como "fuertes elementos culturales y estructurales". Este artículo elabora una cronología de las formas como se han intrincado los ingredientes en este conflicto para producir sus rasgos de intratabilidad. El artículo señala las maneras como se ha configurado este Habitus, consecuencia de elementos estructurales y coyunturales que han conspirado para configurar ciertas prácticas problemáticas de gestión del suelo, y la población en Bogotá y sus múltiples relaciones con el conflicto que supone la urbanización de predios afectados por la declaración en 1976 de la Reserva natural de carácter nacional Bosque Oriental de Bogotá.

\section{ABSTRACT}

The main conflict intractability features are long duration, pervasiveness and the systematic resistance to conflict resolution attempts, as well as the state role and disputes over fundamental needs, seen as strong "cultural and structural issues". This article focuses in the ways in which, through time, it has been constructed a "Habitus" prone to conflict intractability as a consequence of temporary and structural elements related to particularly problematic land planning and population management practices. The article also points out the complex and entangled relations between the features of intractability with the conflict generated by the urbanization of holdings affected by a National Forest Reserve declaration in Bogotá.

\section{RESUMO}

Os principais rasgos de intratabilidade nos conflitos são: a longa duração; recorrência e fracasso das tentativas de transformação; incorporar o Estado; a luta por necessidades fundamentais; assim como "fortes elementos culturais e estruturais". O texto elabora uma cronologia das formas como se têm intrincado ao longo do tempo os ingredientes deste conflito para produzir os seus rasgos de intratabilidade. $\mathrm{O}$ artigo assinala as maneias como se tem configurado este "Habitus" como consequência de elementos estruturais e conjunturais que têm conspirado para configurar certas as práticas problemáticas de gestão do solo e a população em Bogotá e as suas múltiplas relações com o conflito que supõe a urbanização de prédios afetados pela declaração em 1976 da Reserva de caráter nacional Bosque Oriental de Bogotá. 


\section{Introducción}

El presente artículo busca mostrar las formas como a lo largo del tiempo se ha configurado un Habitus $^{\mathrm{l}}$ proclive a la intratabilidad ${ }^{2}$, manifiesta en la intrincada mezcla de actores, relaciones e ingredientes presentes en la contradicción que supone la urbanización no planificada de predios afectados por la declaración de la Reserva del Bosque Oriental de Bogotá. De acuerdo con Azar (1990, 1991) y Lewicky, Gray \& Elliott (2003), los principales rasgos de intratabilidad son: la larga duración y recurrencia, fracaso de los intentos de transformación, involucrar al Estado, la lucha por necesidades fundamentales, así como "fuertes elementos culturales y estructurales".

A manera de contexto, este trabajo elabora una cronología de las formas como se han urdido a lo largo del tiempo los principales ingredientes en este conflicto para producir la intratabilidad. Para lo cual, se presenta, de una parte, una secuencia crítica de los orígenes y efectos de las prácticas urbanistas puestas en marcha y, de otra, la trayectoria de la urbanización informal en la ciudad, sus efectos y relaciones sobre la Reserva. Para ello, se realizó una revisión detallada de libros, textos de investigación y consultorías (entre otros) y así trazar una historia del urbanismo y sus prácticas, sus efectos y relaciones con los orígenes y desarrollo de la informalidad como categoría anormal, el uso de los recursos naturales, dinámicas políticas e institucionales de regularización y sus interrelaciones con la expansión de la urbanización formal e informal de predios afectados por la declaración de la Reserva.

El documento se divide en cinco secciones. La primera de estas explora los orígenes coloniales de la tradición de depredación de los recursos naturales, sus relaciones con la debilidad institucional y la segregación socio-espacial. La segunda sección recorre las prácticas de planeación urbana aclimatadas a diferentes lógicas y visiones de la planeación urbana y sus efectos sobre la especulación con el suelo y el modelo expansivo actual. La tercera aborda los años setenta, cuando se declara la Reserva en un momento cumbre de la protesta, el crecimiento urbano no planificado y la pobreza urbana, articulados efectivamente al dispositivo clientelista. La cuarta sección explora las maneras como el Ajuste Estructural, el paradigma de Desarrollo Sostenible y el Giro Espacial conspiran para generar una sobreproducción de normas ambientales en un contexto de desregulación urbana proclive a la ambigüedad y discrecionalidad lo que, unido a los demás rasgos de intratabilidad, ha complejizado y magnificado la permanencia irresuelta de este conflicto y caracterizado los fracasos de los repetidos intentos de transformación. Por último, se presentan algunas reflexiones.

\section{Depredación ecológica, debilidad institucional y segregación e inequidad}

La recurrencia y larga duración de la dinámica de ocupación expansiva y conflictiva
${ }^{1}$ El Habitus corresponde a "las estructuras que son constitutivas de un tipo particular de entorno (v.g. las condiciones materiales de existencia de un tipo particular de condición de clase) y que pueden ser asidas empiricamente bajo la forma de regularidades asociadas a un entorno socialmente estructurado, producen Habitus, sistemas de disposiciones duraderas, estructuras estructuradas predispuestas a funcionar como estructuras estructurantes" (Bourdieu, 1977, p. 175).

${ }^{2}$ La noción de Intratabilidad emergió de los Estudios de Paz, el término Protracted Social Conflicts (Conflictos Intratables) fue acuñado por Edward Azar en los años setenta para referirse a conflictos violentos caracterizados por: su larga duración, la elusión de los repetidos intentos de resolución, el incluir la lucha pornecesidades fundamentales e involucrar "aspectos estructurales". En los años ochenta la Escuela Norteamericana acuñó el concepto de Environmental Intractable Conflicts, para referirse a conflictos por recursos naturales con características similares, pero no necesariamente violentos (Azar 1985, 1990, 1991).

territarias 36

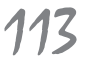


del territorio y población de Bogotá a lo largo de su existencia ha sido efecto de la puesta en marcha de una ciertas lógicas de ordenamiento del territorio y gestión de la población. Estas han resultado en la segregación socio-espacial y la adopción de formas depredadoras e inequitativas de gestión de su recursos naturales. Dichos elementos han enmarcado la emergencia de los principales rasgos de intratabilidad del conflicto.

\section{La ciudad como dispositivo del aparato extractivo y segregacionista}

En 1551 con la instauración de la Real Audiencia se establecieron los partidos de Bogotá, Suba, Ubaque, Pasca y Fusagasugá. Estos comprendían 53 pueblos de indios que debían ser reducidos como parte de las políticas segregacionistas y de "protección a los aborígenes" (Zambrano, Casteblanco, Sánchez, Hoyos, Ruíz \& Benninghoff, 2000). El título de ciudad dependía de la importancia del asentamiento en función de su distancia a los puertos y los recursos explotables. Las principales ciudades eran puertos, centros mineros o centros de recaudo: Santafé de Bogotá, Cartagena y Popayán (Murad, 2003, p. 11). Como depositarias del monopolio tecnológico y comercial imperial las ciudades recolectaban tributos, regulaban la extracción de recursos, así como el envío a la metrópolis de mercancías producidas o extraídas bajo sistemas esclavistas o serviles, que incorporaría la importación de mano de obra es- clava debido a la reducción de la población indígena (Quijano, 1993, p. 204).

En el caso de Bogotá, su fundación fue determinada por la disponibilidad de riquezas y, sobre todo, de mano de obra indígena sometida. Los imperativos de control militar hicieron que creciera con los Cerros cubriendo la retaguardia, peligrosamente cerca de los nacimientos de agua (Mejía Pavony, 2012). La abundancia hídrica dada por las numerosas quebradas y ríos que descendían de los cerros, cumplieron su papel tanto en determinar su morfología, como en que fuera muy poco valorada como recurso (Preciado, Leal \& Castañeda, 2005; Castro, 2005; Rodríguez \& Villegas, 2003).

En efecto, los gobiernos locales mostraron poco interés por el uso adecuado no solo del agua sino de la fauna y el bosque. Se construyó así una percepción de abundancia que los subvalora y depreda. Adicionalmente, el cuidado y provisión de agua y leña estaba a cargo de los indígenas y mestizos pobres, en particular sus mujeres, lo cual explica por qué los sistemas de manejo, tratamiento o siquiera conducción de aguas residuales no fueran considerados como prioritarios por las autoridades. Esto se evidencia en la ausencia de un sistema de alcantarillado hasta bien entrado el siglo XX a pesar de la fundación de Bogotá en 1538. Este fenómeno que se repite hoy, en muchas ciudades importantes en $\mathrm{Co}^{-}$ lombia que no cuentan con acueductos o alcantarillados. Los numerosos, costosos y dilatados esfuerzos para su construcción, así como la dependencia de tecnología, 
capital y saberes del Norte, son ejemplo de una larga tradición de fragilidad en la gestión. En 1908, el municipio encargó el diseño del alcantarillado, en un intento por solucionar el grave problema de las aguas servidas corriendo por la superficie de las calles, a la empresa inglesa Pearson \& Sons. Esta tuvo que levantar los planos de la ciudad ya que no existían. En 1915 se elaboraron los nuevos planos y en 1927 se celebraron los contratos de construcción con la Casa White de Nueva York. Los técnicos de esta compañía se encuentran con que los planos se perdieron y deben levantarse de nuevo (Rodríguez et al, 2003).

Entre 1929 y 1932 Ullen \& Co construyó el acueducto que, en solo tres años, requiere ser ampliado. En 1935 se ejecutan las obras del embalse de La Regadera, captando el agua de los ríos Blanco, Tunjuelo y Teusacá para conducirlas a Vitelma que entró al servicio en 1938 (EAAB, 2003; Preciado et al., 2005, p. 143). Como consecuencia de la alteración del cauce y la toma de agua para La Regadera, el río Tunjuelo, el más extenso de la ciudad y que atravesaba Usme, Bosa, Ciudad Bolívar y Tunjuelito alimentando una amplia red de humedales, es desecado generando graves impactos ecológicos y sociales, al tiempo que creó una inesperada oportunidad para los latifundistas: la urbanización de los predios desecados (Martínez, 2010). Osorio $(2007,2010)$ reconstruyó la historia de la cuenca del río Tunjuelo, sus habitantes y su destino de pobreza y destrucción con el fin de proveer agua para la ciudad. A estas intervenciones hidráulicas seguirán, con la misma lógica de depredación y contaminación, la sepultura de los ríos San Francisco y San Agustín.

La debilidad institucional, dependencia de saberes, capitales y técnicas del Norte, poca valoración de los recursos naturales, depredación y transferencia del grueso de los costos ecológicos y sociales de los proyectos urbanos a las periferias y, por ende, a los grupos menos poderosos que las habitan han sido una constante. Esto no solo ha perpetuado la desigualdad y segregación norte-sur en la ciudad, sino que produce violencia estructural, dada su injusticia ambiental. En el sur se han ubicado equipamientos, rellenos sanitarios, centros mineros y las plantas de tratamiento de aguas residuales generando graves impactos sobre la calidad de vida y salud de sus pobladores, además de desvalorizar sus predios (Méndez et al., 2006). Estas prácticas institucionalizadas han contribuido a magnificar la protesta urbana y lucha por necesidades fundamentales uno de los principales rasgos de la intratabilidad.

\section{Importación de saberes y prácticas urbanistas}

A finales del siglo XIX las élites colombianas enfilaron sus esfuerzos para producir centros urbanos bajo parámetros “modernos". Los gobiernos firmaron tratados de libre comercio y se embarcaron en sendos procesos de modernización financiados con la concesión de extensos territorios y un fuerte endeudamiento dirigido a crear o fortalecer instituciones de gobierno, fi- territarias 36

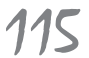


${ }^{3}$ Cambios que se tradujeron en: 1) la liberación de flujos humanos antes atados a la tierra; 2) la sanción de leyes y politicas (disolución de resguardos, fomento tabacalero, bonos de deuda, ley de "manos muertas", los intentos de separación entre Estado e Iglesia, las concesiones y politicas dirigidas a promover la inversión de capital extranjero, etc.); 3) la multiplicación de medios de comunicación y transporte entre 1880-1930 , sine qua non de las iniciativas de libre comercio, en particular con Inglaterra, $y$ los tratados de "libre navegación y amistad" con distintospaises; 4) la expansión territorial productiva; 5) la libertad de culto, de asociación, para poseer armas y municiones, y comerciarlas, y por ultimo no por eso menos importante y 6) la instalación en el imaginario de las elites de los nuevos paises del deseo de emular las urbes de los paises del norte.

${ }^{4}$ 1851, 1854, 1860-1862, 1876-1877, 1885, $1895 y$ 1899-1902, hasta alcanzar una relativa estabilización a comienzos del siglo XX con la victoria de la regeneración conservadora.

5 Paris, Filadelfia, San Francisco, Barcelona, etc. La de Paris celebraba los 100 años de la Revolución Francesa y la de Filadelfia, en 1876, la Independencia de Estados Unidos.

\section{territarias 36} 116 nancieras, académicas (escuelas técnicas, normales), modelos de gestión, financiación de infraestructura de servicios públicos y comunicaciones necesarios para "la articulación a la economía mundial" (vías, puentes, puertos fluviales y marítimos y tendidos de redes ferroviarias). Bajo la denominada "división poscolonial del trabajo" (Saldarriaga \& Manuel, 2012) se buscaba materializar "relaciones modernas" impulsadas por el imperativo de la movilidad $^{3}$ y liberalización, en contraposición a la lógica Colonial de estatismo, fuerte intervención institucional, el estricto control económico (el monopolio comercial y los estancos), cultural, social y racial y la marcada injerencia de la Iglesia.

Estos cambios presionados por el discurso moderno, no se dieron sin resistencias y originaron recurrentes guerras civiles durante casi todo el siglo XIX ${ }^{4}$. El país sufrió un gran estancamiento demográfico, promulgó siete constituciones distintas, perdió a Panamá y otros territorios y pasó por cuatro nombres antes de bautizarse República de Colombia.

Desde finales del siglo XIX y comienzos del XX, las élites produjeron los pilares culturales para imaginar y desear una ciudad moderna. La celebración del Centenario del nacimiento de Simón Bolívar (1883) y la conmemoración de los cien años de la Independencia con la Exposición Agrícola e Industrial (1910), fueron resonancias locales de las Exposiciones Universales $^{5}$ (Castro Gómez, 2009). En Bogotá, bajo esta lógica, se importó la planeación urbana que se materializó en la apertura de vías y dinámicas expansivas. Esto dio inicio a una tradición de especulación y generación de grandes plusvalías para los terratenientes por efecto de los cambios de uso del suelo. De acuerdo con Castro Gómez (2009), los límites geográficos, económicos y sociales fueron rotos con la construcción de las vías férreas y avenidas, con la puesta en marcha primero del tranvía de mulas (1899), luego eléctrico en 1910 y los trenes. El Ferrocarril del Sur unió al centro con Soacha, mientras el ferrocarril del norte lo conectó con Zipaquirá y Nemocón (Zambrano et al., 2000, p. 233). La ciudad cambiaba; los nuevos equipamientos urbanos (ferrocarril y vías) transformaron las características y usos de los caminos de origen prehispánico, así como a las haciendas que cruzaban, dando lugar a un auge urbano especulativo, frente al cual se trazó el primer intento de perímetro en 1914 (Acuerdo 6).

La estación de la Sabana (1917), conectó el occidente y obligó la construcción de la Avenida Jiménez. Mientras, la ampliación de la Carrera Séptima unió a Chapinero y el norte de la ciudad. Hasta la construcción de las nuevas vías, el norte había estado limitado por la "franja vacía" que constituía el Colegio de San Bartolomé, el Polo Club (Calle 34 a 39 entre las Carreras 13 y 14) y el Hipódromo de La Magdalena. Límites rotos con la construcción de la clínica Marly y ocho manzanas residenciales (Castro Gómez, 2009 , p. 108). Zambrano et al. (2000, p. 232) explican el desarrollo Norte-Sur de la ciudad en razón de que el Ferrocarril 
de Cundinamarca, propietario de extensos territorios de occidente, sus redes San Façón, Paloquemao, La Sabana y Paiba, impedían la expansión, no teniendo el crecimiento urbano otra opción que bordear sus terrenos y crear un gran vacío que se mantuvo hasta los años 80 .

Uno de los primeros en visionar las oportunidades de expansión urbana de élite que ofrecían las haciendas en el norte y los cerros fue José María Sierra, quien, hacia 1880, había evidenciado este proceso en Medellín, ciudad con mayores limitaciones de expansión por sus características geomorfológicas, lo que lo incentivó a la compra y monopolio de las haciendas ubicadas en el norte, aprovechando la crisis económica del liberalismo resultado de las guerras civiles, el mal manejo económico de los gobiernos y la práctica de realizar remates de tierras para obtener recursos (Jaramillo, 1947).

Mientras tanto en los cerros circundantes y cinturones de miseria se construía otra ciudad en función de la necesidad. Viviendas para los obreros de las fábricas recién instaladas: vidrio (1834), chocolate (1887), cerveza (1889) y cemento (1905). Así como para una enorme masa de desposeídos encargados de extraer insumos y suministros para la urbe en eterna y voraz expansión: leña, maderas, piedra, arena, carbón y cocinar ladrillos en los chircales. La población rural vecina, compuesta por una mayoría de indios libres convertidos en agregados, peones y jornaleros eran los encargados de la producción y suministro de alimentos (leche, carne frutas, hortalizas, tubérculos y cereales) de las haciendas de la Sabana y Ubaté (Mejía Pavony, 2000).

En 1905, a pesar de contar con cien mil habitantes y de urbanizarse rápidamente, Bogotá estaba lejos de ser una gran urbe. Para ello debía vencer no pocos obstáculos culturales, económicos y sociales. Entre ellos, estar cercada por haciendas y antiguos señoríos que limitaban el funcionamiento de los mercados de tierras. Pero, sobre todo, resolver las tensiones sociales y políticas subyacentes a las formas de organización del trabajo, así como la recurrencia de epidemias causadas por la pobreza, el hacinamiento y la insalubridad. No se contaba con un acueducto ni sistema de alcantarillado eficiente. Recursos como la leña y el agua limpia se hacían cada vez más escasos por cuenta de contaminación por basuras, aguas negras, mataderos, curtiembres y vertimientos de desechos fabriles unido a una acelerada tala, pérdida, intervención y contaminación de ecosistemas valiosos como los Cerros Orientales, los humedales, quebradas, ríos y bosques circundantes (Palacio, 2008, p. 138).

Frente a los problemas más apremiantes se realizaron varios intentos de higienización y reforestación exótica, así como de regulación del crecimiento urbano. Pero la acumulación de tres siglos de extracción de recursos y débil gestión mostraban sus efectos: una alta mortalidad - mayor que la natalidad-, una elevada crisis higiénica y de salubridad, escasez de recursos energéticos, déficit de vivienda, hacinamiento y epidemias a lo que se sumaba la inconformidad y protesta social. Esta era la territarias 36 
situación del Paseo Bolívar, un gran cinturón de miseria (asentamiento informal, se diría hoy) que se extendía a los pies de los Cerros desde la Plaza de Egipto hasta el Parque de la Independencia en donde en 1922 habitaban cerca de treinta mil almas, la mayoría desplazados por la Guerra de los Mil Días. En 1918 sucedió lo inevitable: una epidemia de gripa española contagió al $80 \%$ de la población y cobró la vida de cerca de mil quinientas personas. Fue un trágico llamado a la importancia del mejoramiento de las condiciones higiénicas y de salubridad de la ciudad (Castro Gómez, 2009, p. 130).

\section{Llegada de Karl Brunner}

En 1919 fue creada la Sociedad de Mejoras Públicas de Chapinero para seguir los principios modernos promulgados por Olano en Medellín. Como eco, a finales de 1920 se creó el Departamento de Urbanismo de Bogotá adscrito a la Secretaria de Obras Públicas y se nombró a Brunner director. En 1925, hizo su aparición el documento de planeación "Bogotá Futuro" que, bajo las directrices del city planning anglosajón, establecía los criterios para controlar y adoptar la forma de ciudad como instrumento para "corregir los patrones de expansión incontrolada" (Zambrano et al., 2000, p. 238).

En general, las intervenciones e intentos de planeación del crecimiento de Bogotá hasta la llegada de Karl Brunner en 1933, pueden caracterizarse como puntuales e inconexas. Respondían a eventos cir- cunstanciales relacionados con problemas sanitarios, la apertura de vías y tendido del trazado férreo (Alcaldía de Bogotá, 2010; Preciado et al., 2005). Bogotá inició sus prácticas de gestión de la población y adoptó principios de control sobre su configuración guiada por las ideas de "progreso, orden y civilidad" con la construcción de un entorno físico (transporte, parques y bulevares) que propiciara no solo la acumulación y producción de plusvalías por la vía fabril, sino la producción de subjetividades obreras urbanas disciplinadas e "higienizadas" cuyos hábitos, moral y adiestramiento se consideraban inadecuados para las maneras y requerimientos de la sociedad industrial tan deseada no solo por las élites, o los gobernantes, sino, por la Iglesia.

Pero los sueños industrializadores de las élites, incluidos sus deseos de ciudad a imagen del Norte, no eran del todo compatibles con la realidad del país. A pesar del rápido crecimiento económico y urbanización de Bogotá, que daba por cierta "la civilización", a comienzos del siglo XX Colombia era un extenso territorio de más de un millón de kilómetros cuadrados con una población de algo más de 4 millones de habitantes, solo el $20 \%$ ocupaba las cabeceras (Flórez \& Romero, 2010).

Adicionalmente, estaba precariamente conectado por una incipiente red de comunicaciones y mercados. Pero, sobre todo, mantenía una economía de enclaves regionales, basada en relaciones serviles y extracción intensa de recursos naturales, regentada por una pequeña élite de inver- 
sionistas de diferentes países europeos y Estados Unidos, que comandaba un grueso de población indígena o mestiza desposeída, analfabeta y sin derechos políticos ${ }^{6}$.

La Bogotá formal era habitada por terratenientes herederos del poder español y un puñado de extranjeros ligados a las familias poderosas locales por alianzas familiares y exportaciones primarias y extractivas características del Sur a comienzos del siglo XX. Mientras la ciudad de los pobres, en contraste, se construía de manera espontánea por las presiones de la búsqueda del sustento con ayuda de intervenciones puntuales y asistencialistas de la Iglesia Católica y la labor caritativa de las damas grises.

Brunner, bajo la coyuntura liberal de "La Revolución en Marcha", dio inicio a una época dorada de inversión, regulación y planeación urbanística sin equivalentes, en el que el municipio y la nación se asociaron en la construcción de obras públicas de calidad. Trazó vías emblemáticas como la Caracas y urbanizó barrios hoy icónicos ${ }^{7}$. En los terrenos de los Cerros recuperados del Paseo Bolívar, diseñó el Parque Nacional como pulmón de la ciudad (Colón, 2005) y expulsó a los grupos de artesanos del barrio El Carmelo (Serna \& Gómez Navas, 2012; Zamudio, 2010).

Entre 1936 y 1946, se construyeron numerosos barrios en el norte (La Cabrera, El Nogal y El Retiro) hasta llegar a la Calle 87 con un mosaico de residencias de élite ${ }^{8}$. En el sur, se avanzó hasta la Calle 24 sur. Mientras, al occidente alcanzó la carrera 30. Bogotá adquirió un definitivo aire de modernidad bajo intervenciones de Brunner, doctor en urbanismo con obsesión por el hábitat de calidad bajo los principios de la Ciudad Jardín. Su gestión dio lugar a un trabajo bajo los parámetros de planeación moderna e higiénica, trazado de vías, diseño de barrios y célebres transformaciones no exentas de algún grado de injusticia.

Como consecuencia de las medidas de higienización y ampliación de las vías hacia el sur, se fortalecieron las dinámicas especulativas con el suelo de la periferia. Las haciendas fueron loteadas para ofrecer viviendas obreras. La Sociedad Católica de San Vicente de Paul, desarrolló el barrio obrero Villa Javier (Londoño \& Saldarriaga, 1994). Entre 1905 y 1919 se ofrecieron planes de autoconstrucción para obreros y empleados mediante crédito a largo plazo de bancos capitalinos. Se financió la construcción de los barrios: Inglés, El Claret, La Perseverancia, Ricaurte, Córdoba, 20 de Julio, Primero de Mayo, Buenos Aires, Las Cruces y San Cristóbal (Alcaldía de Bogotá, 2010).

1930 marcó un hito en la expansión hacia el occidente con un número importante de obras a pesar de los obstáculos que ofrecían los terrenos del ferrocarril, los humedades, las chucuas y, en alguna medida, las haciendas sin interés en la especulación. Se inició la construcción del campus de la Universidad $\mathrm{Nacional}^{9}$, el aeropuerto de techo en los antiguos terrenos de la hacienda Timiza de López Pumarejo, que se mantendrá en funcionamiento hasta 1959 y se construyó el estadio Nemesio Camacho "El Campín”
${ }^{6}$ Solo los hombres mayores de edad, alfabetos y propietarios podian votar.

7 Teusaquillo, Bosque Izquierdo, La Magdalena, Palermo, San Luis y El Retiro con equipamientos de alta calidad (avenidas, parques y colegios). De la misma manera, fueron trazados y construidos media docena de barrios para la clase obrera: El Barrio Inglés, El Claret, El Centenario y el barrio Popular Modelo, entre otros.

${ }^{8}$ La gran mayoría hoy demolidas y diseñadas por arquitectos extranjeros como Leopoldo Rother, Victor Schmidt y Vicenzo Nassi.

${ }^{9}$ Con diseños de Leopoldo Rother, Fritz Karssen, Ernesto Blumenthal, Alberto Wills y Erick Lange.

territarias 36 119 
${ }^{10}$ En la hacienda de Juan Aranda cuya existencia data de 1573, en la confluencia de los ríos Chinua y San Agustín.

${ }^{11}$ Calderón Tejada (19341938), Granjas de Techo (1938) y Divino Salvador (1940-1942).

${ }^{12}$ A lo cual habian contribuido en mucho los muertos y heridos producto de revueltas campesinas en las haciendas cafeteras del Chocho y El Sapo, en el Tequendama.

13 Tal como narró García Márquez en Cien Años de Soledad y documentó el investigador Renán Vega Cantor.

\section{territarias 36} 120
(1938), proyectado por Gaitán durante su periodo como alcalde. Occidente iba siendo ocupado por manchas urbanas, debido a la presencia de numerosos humedales que luego se desecarían, como fue el caso de Puente Aranda ${ }^{10}$. Estos terrenos conformaron en la calle 13 la futura zona industrial por cuenta del beneficio que ofrecían las antiguas vías rurales modernizadas (el antiguo camino a Fontibón que conducía a Honda y la futura avenida Las Américas a imagen de los Campos Elíseos) que, mediante la desecación de los humedales, permitían conectar con el resto del país.

En 1932 se creó el Instituto de Crédito Territorial (ICT) con el fin de conceder crédito para viviendas obreras y migrantes. Bajo su gestión se crearon numerosos barrios $^{11}$ obreros en el occidente, excepto el Calderón Tejada. Ante la crítica presión de las necesidades de vivienda, se creó en 1935 la Comisión Permanente de Habitaciones, para construir barrios para empleados de las empresas municipales que buscaba sustituir las barriadas insalubres. Sin embargo, los recursos terminaron por "redirigirse" a la construcción de la avenida Caracas para celebrar el cuarto centenario en 1938.

Fiel a su dinámica, y a pesar de las enormes disparidades sociales y de las protestas civiles, Bogotá en 1938 concentraba una creciente actividad económica: contaba con 144 establecimientos comerciales, 506 talleres y 106 depósitos y garajes. Para 1945 el número de establecimientos industriales era de 1060. Durante este periodo la capital ocupaba al $30 \%$ de la población empleada del país y concentraba $38 \%$ del capital total nacional (Palacio, 2008, p. 130 a partir de Velásquez, 1989).

El partido liberal había logrado con la reforma a la Constitución colombiana de 1936 la sanción del derecho a la libre empresa e iniciativa privada, en otro intento de liberar las relaciones de producción y generar una respuesta moderna a la muerte de la Hacienda y las relaciones serviles en el campo ${ }^{12}$.

En la adopción de los cambios constitucionales influyó la tristemente célebre matanza de las bananeras que sobrevino a la huelga y protestas de los trabajadores de la United Fruit Company por las condiciones de explotación y violencia a las que los obreros eran sometidos ${ }^{13}$. De forma paralela al crecimiento urbano y transformación urbanística, la capital y el país eran sacudidos por marchas, reclamaciones, mítines y huelgas que alcanzaron su clímax en 1945 (Perry,1994, p. 239).

Con el fin de subsanar las limitaciones de los planes piloto que siguieron al Plan Regulador de Brunner (el cual nunca se implementó en su totalidad), fue creada la Ley 88 de 1947 que obligaba a las ciudades a ordenar su expansión física. Bogotá, Cali y Medellín acudieron a los saberes del Norte y, en particular, a la firma norteamericana Town Planning Associate. El Acuerdo 88 de 1948 autorizaba la contratación de expertos internacionales, lo que permitió importar los servicios primero de Jeanneret y Le Courbousier y luego de Wiener y Sert contratados para proyectar la organización espacial de Cali, Medellín y Bogotá con motivo de la Novena Con- 
ferencia Panamericana de 1948. De París viajó Le Corbusier puesto a cargo de los planes Director y Regulador de 1951, que nunca se llevaron a cabo (Palacio, 2008, p. 134; Zambrano et al., 2000, p. 253).

En 1958, como sustituto del plan de Le Corbusier, se formuló el plan Víal de 1957 y Distrital de 1958, dando continuidad a lo que ha caracterizado el patrón de crecimiento de la ciudad: la apertura de vías como forma de abrir mercados a las dinámicas de especulación, valorización del suelo y generación de plusvalías como principal ordenador de su morfología. Así como injusticia y segregación socio espacial como resultado de las intervenciones, y la formulación de costosos planes nunca llevados a cabo.

\section{El Bogotazo, la migración de las élites al norte y el abandono del centro}

A raíz del Viernes Negro, como se bautizó al 9 de abril de 1948, catarsis del descontento político y social, cerca de veintidós manzanas del centro de la ciudad fueron saqueadas y destruidas por parte de las masas enfurecidas luego del asesinato de Gaitán. De modo que se contó con la excusa perfecta para una modernización que antes parecía imposible debido a "la enorme fragmentación de la propiedad y el desorden catastral y legal" (Aprile, 1992, p. 633). El Bogotazo "fue aprovechado para iniciar una política sistemática de intervención privada especulativa en el centro de la ciudad" (Zambrano et al., 2000, p. 255).
El casco histórico percibido como antihigiénico y obsoleto fue o bien marginado o desacertadamente intervenido, dando paso a un lento proceso de degradación con operaciones dirigidas a "abrir la ciudad a la modernidad", bajo los postulados de movilidad lo que dio lugar al levantamiento de los rieles del tranvía, la demolición de claustros, iglesias, hospitales, teatros, edificios públicos y hoteles republicanos ${ }^{14}$. La crisis facilitó una urbanización especulativa más allá del límite de Chapinero y el antiguo Plan de Brunner, centrado en el hábitat y el entorno natural como articulador entre la vivienda, el barrio y los equipamientos, se abandonó completamente bajo una visión del progreso que ignora la memoria colectiva, materializado en la constante trasmigración de las élites hacia el norte. Un urbanismo depredador que construye, ocupa y luego desecha el territorio.

Le Corbusier calculó la población para el año 2000 en apenas un millón de habitantes, en 1964 el Distrito Especial contaba con 1.661.935 habitantes (Aprile, 1992; Preciado et al., 2005). En 1954 Rojas Pinilla lo había creado y con él se anexaron seis municipios vecinos y sus tierras con el fin de legalizar una situación de facto. Su decreto constitutivo (3640) permitió remover los obstáculos a los intereses económicos para continuar con una expansión fragmentada, en la práctica el grueso de las haciendas de estos municipios ya estaban articuladas a la dinámica urbanizadora (Aprile, 1992).
${ }^{14}$ El convento e Iglesia de Santo Domingo demolidos en 1946 para construir el edificio Murillo Toro del Ministerio de Comunicaciones, el Convento de San Agustín demolido en 1940 para construir el Ministerio del Interior y el de San Francisco para construir la Gobernación de Cundinamarca. Otros conventos demolidosfueron: La Candelaria, Santa Inés y El Carmen. Santa Inés, demolida para la ampliación de la carrera décima en 1950.El Hospital de huérfanos para ampliar la carrera decima. El edificio Rufino José Cuervo edificado en 1891 yel Hotel Granada y Regina en el Parque Santander para ampliar la Jiménez.

territarias 36

121 
Los planes de Le Corbusier, centrados en la funcionalidad moderna, fueron abandonados en algún momento entre 1956 y 1957 obedeciendo a distintas razones entre las que se encontraban: 1) No estar acorde con las expectativas de la Junta Militar (Aprile, 1992, p. 647); 2) Ir en contra de los intereses de los latifundistas más interesados en la expansión urbana, desregulación y especulación del suelo; 3) La débil capacidad institucional técnica, de comando y control de la ciudad y, sobre todo, 4) la subestimación del crecimiento urbano en el contexto de migración forzada. A continuación, y en la mejor tradición de la planeación urbana bogotana, ninguno de los planes ni diseños de los expertos contratados se pondrán en marcha, reinando en su reemplazo los Planes Viales por obvias razones (Ramírez, 2011).

La autopista norte propició la expansión especulativa sobre las tierras de cultivo de la Sabana y la concentración de un equipamiento que ha contribuido a ampliar la segregación socio-espacial. Los vacíos entre vías se configuran de forma fragmentaria y al ritmo de la especulación en áreas residenciales y conjuntos de carácter segregacionista, mientras en las áreas más degradadas se establecen los asentamientos informales periféricos:

La ciudad se construye a partir de estructuras físicamente segregadas en las que predomina la repetición de la unidad de vivienda. No existen vínculos simbólicos que promuevan la cohesión social. Se trata, entonces, de una ciudad periférica que gira alrededor de un eje viario arterial del que se desprenden conjuntos homogéneos de calles y manzanas, sin ningún punto de referencia (Díaz, Gómez, González, Secretaría Distrital de Planeación \& Universidad Nacional de Colombia, 2007, p. 21).

En el sur, las nuevas áreas habitacionales que surgen bajo este modelo (Ciudad Bolívar, Soacha y Usme) son cada vez más marginadas en términos de servicios y equipamientos:

Se traza, entonces, la frontera entre ricos y pobres, ya no sobre la base del linaje de la sangre, como había ocurrido en la colonia, sino sobre el paradigma de la riqueza [... El norte pasa a ser el espacio de la modernidad, mientras que el centro y el sur continuaron siendo el espacio colonial de antaño, aquello que debía ser «rebasado» por el progreso (Ospina, 2010, p. 338).

Desde el punto de vista de los efectos de estas dinámicas y sus relaciones con el conflicto que supone la expansión urbana no planificada en la ciudad, se aceleraron la depredación de los recursos agua, suelo y bosque. En la Reserva en particular se llega a un nivel dramático, por lo cual, la cara de los Cerros fachada de la ciudad, es objeto de un programa de reforestación con especies importadas (pinos y eucaliptos) que, si bien los vistió de verde, generó graves daños ecológicos al expulsar la fauna nativa y elevar los riesgos de incendios en las temporadas secas, entre otros (Salamanca \& Camargo, 2000; Camargo 2001, 2002). 
Durante este período, la acelerada migración y pobreza magnificada por el conflicto armado será un elemento estructural que, unido a las practicas inequitativas de gestión del territorio y la población, abandono de proyectos, la insuficiente oferta de vivienda obrera y servicios, la tradición de especulación con la tierra mediante los planes viales y el reasentamiento involuntario por las obras públicas, agudizaran el conflicto de la autoproducción del hábitat en la Reserva.

\section{Los años setenta: el clientelismo, un efectivo dispositivo de urbanización informal, articulado a la migración en un contexto de conflicto armado}

Los años setenta se caracterizaron por ser un período de gran agitación política y social en el marco de: 1) El desmonte del Frente Nacional, concebido como un pacto entre los dirigentes del partidos liberal y conservador luego del derrocamiento de Rojas Pinilla ${ }^{15}$; 2) el aplazamiento y transferencia de las presiones del conflicto por la tierra a las zonas de colonización y reservas forestales declaradas por la Ley $2^{\mathrm{a}}$ de 1959 ; 3 ) el fracaso de los intentos de reforma agraria, unido al escalamiento inflacionario y aumento de la pobreza urbana; 4) el apogeo de los movimientos de lucha por la tierra -indígenas, campesinos-y los paros cívicos nacionales, en especial el de 1977, y 5 ) la expansión y fortalecimiento de grupos insurgentes rurales y urbanos en las zonas periféricas.

Se calcula que el $40 \%$ de los barrios de Bogotá crecieron y se consolidaron de manera informal. Era la única alternativa frente a: 1) la baja capacidad de pago de los propietarios, 2) el anacrónico déficit de vivienda y constantes demanda de techo generadas por los recurrentes ciclos de migración de campesinos; 3 ) la intensa especulación con el suelo urbano (Arango, 1981; Martínez, 2007; Torres Tovar \& Castillo, 2005; Torres Tovar, 2007) y 4 ) la tradición de inequidad y segregación socio-espacial desde los tiempos coloniales (Puente Burgos, 2005; Zambrano et al., 2000).

En 1970 más del $50 \%$ de la ciudad - 13.985 Has. - correspondía a desarrollos informales (Martínez, 2007). Estudios de Torres Tovar (2007) y Hataya (2010) señalan que el grueso de estos asentamientos son originados por el loteo ilegal o pirata mediante el uso de "profesionales de la urbanización ilegal" o "tierreros", como se denomina a los encargados de esta labor no exenta de riesgos dadas sus prácticas ilícitas. En otras ciudades la invasión parece ser más generalizada. Los habitantes de los barrios informales no llegan directamente del campo a los barrios. Primero pasan por inquilinatos y viviendas compartidas en arriendo, hasta que identifican y crean redes sociales para establecerse como propietarios. Esto depende de procesos de movilidad social ascendente y descendente (Georges, 1976; Sánchez Steiner, 2008; Torres Tovar, 2007).
${ }^{15}$ El Frente Nacional permitió a los partidos tradicionales entre 1958 y 1974 alternarse en el poder cada cuatro años y excluir a cualquier otro partido de la arena politica manteniendo una fachada "democrática”.

territarias 36

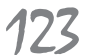




\section{El dispositivo clientelista, las normas y los procesos de regularización}

Si bien entidades públicas, planes y regulaciones, desde el discurso del Desarrollo Urbano, planifican la programación de la inversión para el desarrollo de la ciudad, la realidad es que la mayoría de las ciudades colombianas han mantenido una dinámica asimétrica y dual de crecimiento que articula los procesos de construcción de ciudad formal para unos grupos sociales y la autoproducción del hábitat para otros (los más pobres vulnerables), generando plusvalías de diferentes órdenes que, de distintas maneras, son apropiadas por los grupos con mayor poder. En esta articulación, el patronazgo y establecimiento de redes clientelistas han jugado un papel protagónico contribuyendo a la recurrencia, larga duración y fracaso de los numerosos intentos institucionales para corregir esta “anormalidad" (Dávila, 2002; Díaz Mosquera, 2009). El clientelismo ha probado ser muy eficiente, sus redes acoplan fácilmente las JAC y las intervenciones de regularización del gobierno distrital porque, a diferencia de otros países de Latinoamérica e incluso otras ciudades de Colombia, los procesos no deben superar el más fuerte de los obstáculos: el saneamiento de las propiedades o la titulación de los predios, porque estos, en su gran mayoría, son resultado del loteo ilegal realizado por sus propietarios a través de intermediarios, los tierreros (Ocampo, 2003).

Uno de los numerosos efectos nega-

territarias 36 124 constante expedición de normas ambiguas o contradictorias que evidencian su gran poder en el Concejo de la ciudad. Por ejemplo, el Acuerdo Distrital 68 de 1961, más que prevenir o castigar, buscaba integrar los desarrollos informales luego de un procedimiento técnico de levantamiento cartográfico e incorporación al perímetro de la ciudad, realizar el desenglobe de los lotes y legalizar las escrituras. Este proceso, en sus elementos fundamentales, no ha cambiado en la actualidad y se mantiene articulado a la maquinaria urbanizadora ilegal sin penalizar.

Las normas utilizan indiscriminadamente los conceptos de "legalización, habilitación y regularización" referidos a la intervención de estos asentamientos. En 1963, con la adopción del Acuerdo 22, se estrenó el concepto de "rehabilitación de barrios". En 1967 el Acuerdo 65 ya no hablaba de "rehabilitación" sino de "Urbanizaciones de Desarrollo Progresivo" y en 1972 se expidió el Acuerdo 21 que adoptaba un Plan de Mejoramiento de áreas urbanas de "desarrollo incompleto". Ante la magnitud del fenómeno, se ha consolidado una política de subsanar las deficiencias de la urbanización informal mediante la inversión pública y provisión de espacio público (zonas verdes y comunales). Durante el gobierno de Carlos Albán (1970-1973) se dictan normas que buscaban que se "rehabiliten" 250 barrios "subnormales", se aprueba un acuerdo de normas mínimas de urbanismo "para prevenir la proliferación de barrios clandestinos" y, al mismo tiempo, se derogan 
aquellas normas que prohibían el establecimiento de servicios por encima de la cota de $2700 \mathrm{msnm}$ y fuera del perímetro urbano (Preciado et al., 2005, p. 237).

Urbanizadores piratas políticos como Forero-Fetécua articularon sus operaciones de urbanización ilegal a una amplia red clientelista política en el sur y el occidente de la ciudad mediante su Movimiento de Integración Popular jugando un papel clave en el veloz patrón de urbanización informal. Mariano Porras, socio de ForeroFetécua en muchas de sus empresas políticas y urbanizadoras, es otro ejemplo de corrupción y hábil construcción de clientelas a costa de las necesidades de vivienda.

\section{Los cerros orientales}

$\mathrm{Al}$ impacto acumulado de las actividades extractivas como la tala, canteras y areneras y las productivas como los chircales, se han ido sumando los impactos de las actividades reproductivas (aguas negras y residuos sólidos) por cuenta de las dinámicas de ocupación que dieron lugar a los llamados "tugurios" sobre las laderas de los Cerros que, con el paso del tiempo, sobrepasaron su capacidad de resiliencia. Cifras provenientes del DAPD, citadas por Campo Albán (2012, p. 15), establecen que en 1972 de 184 barrios de los cerros, 106 eran "tugurios" y de estrato bajo, 36 eran considerados de estrato medio y bajo, mientras 41 pertenecían a estratos mediosaltos y altos. Entre 1964 y 1972, el $100 \%$ de la población era de origen migrante ${ }^{16} \mathrm{y}$ su densidad poblacional se había elevado en un $50 \%$. La precariedad de la situación de la población la ilustran las siguientes cifras: la desocupación alcanzaba el 71,7\% del total, mientras que el $63,7 \%$ ocupado eran mineros, conductores y obreros, el $20,8 \%$ maestros de escuela, empleados y vendedores y el $10.7 \%$ se ocupaba en servicios personales. Los problemas sentidos eran: 51,6\% la ausencia de servicios básicos (transporte, agua, alcantarillado) y de salud el 8,9\%, entre otros (Campo Albán, 2012 , p.16). A lo largo de toda la década "la situación de pobreza urbana se agudiza y el desempleo, la carencia de vivienda y la menor oferta de suelo urbanizable son características que empujan cada vez a más familias a zonas que hasta entonces no habían sido contempladas como urbanizables" (Preciado et al., 2005, p. 235 ).

En 1972, durante el gobierno de Albán, se puso en marcha el polémico proyecto de la Avenida de los Cerros que con sus construcción desalojaría a 300.000 habitantes, al mejor estilo del Paseo Bolívar, enmarcado irónicamente en el planteamiento de la "Planeación Participación Acción” en boga por esos días. En la lucha en contra de la construcción de la Avenida, los habitantes de los barrios se enfrentaron a la Alcaldía, a la oficina de Planeación Nacional y a los grandes propietarios de tierras (Chaparro, Mendoza \& Pulido, 1997; Campo Albán, 2012; Russi, 1975). La protesta y la cantidad y variedad de actores enfrentados marcaron un punto de inflexión en las luchas urbanas y el derecho a la ciudad hasta 1974. Los litigios llegaron al Senado de la República, como presenta
${ }^{16}$ Predominantemente de Bogotá, Cundinamarca y Boyacá. territarias 36

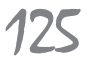


${ }^{17}$ El archivo del Instituto de Estudios Urbanos de la Universidad Nacional presenta un archivo de prensay fotografias que ilustran la protesta: http://www.institutodeestudiosurbanos. info/bibliografias/448bibliografia-piduzob.html

\section{territarias 36} 126
Torres, A., en La Ciudad en la Sombra (1993). Las protestas fueron apoyadas por partidos de izquierda como el Movimiento Obrero Independiente Revolucionario (MOIR), agrupaciones sindicales, ONG, la Iglesia y el CINEP, las JAC y los habitantes de los barrios El Paraíso, San Martín I y II y La Perseverancia.

Finalmente, el proyecto se llevó a cabo con transformaciones en cuanto al trazado de la avenida y sin el apoyo del Banco Interamericano de Desarrollo, el cual cuestionó la ausencia de propuestas sociales integrales para su desarrollo. A pesar de que los comités de pobladores se desmovilizaron luego del desalojo del barrio Girardot ${ }^{17}$ y de la construcción de la avenida, sus lecciones, formas organizativas y demandas fueron incorporadas por otros movimientos y paros cívicos desarrollados en Bogotá en los años siguientes.

A finales de los años sesenta, en las deterioradas laderas de los Cerros, se intensificó la reforestación con bloques de coníferas, acacias y eucaliptos. La falta de manejo y, en particular, de hacer clareos para permitir el restablecimiento de especies nativas generó numerosos problemas ecológicos. La CAR, irónicamente, no podía hacer clareos por la prohibición explicita de extracción de madera en la Reserva, Decreto 2811 de 1974. Adicionalmente, se comienzan a percibir los riesgos por remoción en masa, en especial por construcción sobre antiguas canteras y areneras, así como de inundación por ocupación de rondas de las quebradas (Salamanca et al., 2000; Camargo 2001, 2002).
En cuanto a otras protestas urbanas en la ciudad, Ramírez Soto (1983) y Torres Tovar (2007) estiman que, entre los años sesenta y ochenta, fueron en aumento. Las causas: el abandono del gobierno distrital, la situación de segregación y la baja inversión en las áreas deprimidas del sur. Esta situación no se ha transformado mucho, de acuerdo con estudios de Díaz et al. (2007): "La segregación en Bogotá es elevada, secular y tiende a reproducirse" (p. 2). Las protestas, según Torres (1993) y Molano Camargo (2007), eran resueltas de las siguientes maneras: 1 ) en un tercio de los casos se obtenía una solución, 2) una proporción menor a un tercio encontraba una salida negociada o 3 ) las otras dos formas de manejo eran o bien las promesas o, en últimas, la represión, lo cual, en gran medida, ha contribuido al mantenimiento, recurrencia y limitado éxito de los intentos de manejo.

A pesar de los esfuerzos institucionales dirigidos a prevenir la anormalidad que constituye la urbanización pirata o ilegal, está se ha constituido como una constante en la construcción de ciudad y se ha consolidado como una de las pocas alternativas viables acorde con las capacidades financieras, prácticas culturales y acceso a recursos de los migrantes urbanos. Como vimos anteriormente, al asignarse los recursos públicos prioritariamente a la corrección de las deficiencias de la especulación y la urbanización ilegal, se fortalece su dinámica, enviando la señal a los compradores de lotes que, si bien es una actividad ilegal y punible, el Distrito y la 
maquinaria clientelista terminarán por suplir el equipamiento y servicios necesarios. El conflicto genera una situación donde todos ganan excepto los contribuyentes y los recursos naturales de la ciudad ya que los costos de este modelo depredador y expansivo son transferidos a los ciudadanos por la vía de crédito externo e impuestos. La articulación de la informalidad urbana al dispositivo clientelista es un aspecto que reafirma varios rasgos de intratabilidad: las deficiencias del sistema político, la asimétrica repartición de costos y beneficios, la rentabilidad del negocio urbanizador desde todas las perspectivas y la debilidad del control e impunidad, sumado al fracaso de los intentos de transformación por la vía de la regulación o la sanción.

\section{Algunos efectos del discurso neoliberal y de la conservación sobre la intratabilidad}

Son principalmente dos los tipos de asentamientos urbanizados irregularmente en predios afectados por la declaración de la Reserva en su sección norte. Los primeros, corresponden a los barrios autoproducidos que, a partir del uso de tácticas como la Acción Colectiva, la asociación con $\mathrm{ONG}$ de distintos niveles, así como la articulación de las JAC a redes clientelistas han buscado que el Distrito, a través de sus mecanismos de seguridad, les provea de servicios fundamentales para su supervivencia: agua potable, energía, educación, salud, vías, transporte público, salones comunitarios, etc. (Cuevas \& Vargas, 2004;
Hernández \& Vargas, 2009; Suárez \& Castillo, 2005). Los segundos, son proyectos agenciados por los propietarios de predios, inversionistas de condominios, grandes proyectos urbanísticos, fiducias y gremio de la construcción que, a través de distintas estrategias (incluidas el tráfico de influencias y la corrupción) e invocando “excepciones y parágrafos" en el enorme entramado de normas que permiten el ejercicio de la discrecionalidad en la toma de decisiones, les ha permitido obtener licencias irregulares para urbanizar predios afectados por la Reserva (Contraloría Distrital, 2004; Rico, 2010).

En la actualidad, en el norte, dado el incremento de la demanda y fuerte tendencia de aumento de los precios de la finca raíz, una vez los barrios son legalizados con los esfuerzos de la organización comunitaria y han sido objeto de costosos programas de normalización, son comprados y demolidos para dar paso a un proceso de gentrificación como se evidencia en los barrios Cerro Norte, Bosque Calderón Tejada, Juan XXIII y Los Olivos, entre otros.

A nivel macro, la lógica del neoliberalismo y las medidas de Ajuste contribuyen a tornar críticos otros ingredientes en este conflicto. Primero, al aumentar la vulnerabilidad, pobreza y precariedad como resultado de flexibilización laboral, informalidad y recortes a los programas sociales y con la privatización de servicios básicos (salud, educación, vivienda, etc.) que posibilitan un contexto de incertidumbre laboral y bajo bienestar. Segundo, a partir de los ochenta "La Ciudad de los territarias 36

127 
Promotores" propenderá por reciclar los barrios populares para mercados de clase media alta con grandes beneficios. Tercero, la desregulación urbana y el nuevo modelo de curadurías favorecerán la urbanización suntuaria sobre la Reserva. Por último, y ligado al anterior, las permanentes reestructuraciones del aparato institucional y transferencia de responsabilidades a los débiles, poco capacitados y con pocos recursos niveles locales imposibilitan una adecuada respuesta local al manejo, monitoreo, control y prevención de conflictos de usos del suelo (Brand, 2001).

\section{Híper regulación ambiental, discrecionalidad y ambigüedad}

Desde la declaración de la Reserva en 1976, la producción de normas no ha cesado, así como la recurrente reestructuración, establecimiento de funciones, competencias, zonificaciones, reglamentación de usos, etc. Algunos de estos se hacen para corregir una ambigüedad, incoherencia o contradicción anterior que, a menudo, es utilizada para generar vacíos legales que permiten la discrecionalidad. El decreto 877 de 1976 establecía, por ejemplo, "las prioridades en el uso y gestión del recurso forestal", mientras otro, el Decreto 622 de 1977, creaba el Sistema de Parques Nacionales Naturales y "los reglamentos generales aplicables a estas áreas" sin distinguir claramente las categorías y objetos de conservación. De modo que se producen normas punitivas como el Decreto Ley 100 de 1980 que sanciona la ocupación ilícita de parques y zonas de reserva y adiciona nuevas normas (Acuerdo 53 de 1981 de la CAR y Acuerdo 59 de 1987 de la CAR).

El Acuerdo 6 de 1990 creó una figura de conservación mediante el Título II, Capítulo X, estableciendo "zonas de preservación del sistema orográfico" como franja suburbana de los Cerros Orientales entre los 2700 y $2800 \mathrm{msnm}$, al tiempo que reglamentaba los procedimientos para su urbanización e incorporación al suelo urbano lo cual ha introducido una clara contradicción al establecer un procedimiento para, por vía de Acuerdo del Concejo Distrital, dictar las normas de los tratamientos, incluidos los de preservación. De esta manera, se obtuvieron licencias para proyectos como Mabruk (159.000 $\mathrm{m}^{2}$ ), las Torres del Metropolitan (15.000 $\left.\mathrm{m}^{2}\right)$, los proyectos La Punta y las Delicias $\left(298.177,86 \mathrm{~m}^{2}\right)$, Cerro Verde (13.412,74 $\mathrm{m}^{2}$ ), San Jerónimo del Yuste (296.808.999 $\left.\mathrm{m}^{2}\right)$ y Bosques de Karón (52.421.45 m²), entre otros, que en este momento se encuentran en disputa (DAPD, 2004; Contraloría Distrital, 2004).

Si bien las leyes 99 de 1993 y 388 de 1997 buscaban la planeación de los asentamientos urbanos desde una visión territorial y bajo pautas del discurso de la Conservación y el Desarrollo Sostenible, lejos de mejorar el accionar y elevar las consideraciones por el medio ambiente han adicionado más ambigüedades. Las combinación y superposición de normas encaminadas a la gestión del recurso bosque, cuencas, la conservación y el ordenamiento territorial, entran en contradicción 
no solo con las actividades tradicionales de los campesinos de los Cerros, sino con las expectativas de legalización de barrios populares y las expectativas de urbanización de predios por parte de sus propietarios, las prácticas mineras y la construcción de centros educativos, lo que propicia el uso de diferentes tácticas y estrategias que aumentan la complejidad de las contradicciones y los ingredientes del conflicto en términos de intereses, posiciones y necesidades enfrentadas y a veces percibidas como irreconciliables.

Los fuertes intereses económicos enfrentados a las restricciones del Plan de Ordenamiento Territorial hacen que los constructores utilicen diferentes estrategias para obtener licencias de construcción y decretos de incorporación al suelo urbano de la ciudad para predios afectados por la Reserva, enviando la señal que la ley se aplica discrecionalmente. Lo cual, de una parte, genera numerosos obstáculos a los intentos de legalización de los barrios autoproducidos o la densificación de los barrios informales como alternativa de transformación del conflicto, mientras de otro, no contienen la urbanización suntuaria bajo etiquetas de proyectos ecológicos o de reforestación como el caso de Puente Chicó o los proyectos citados.

En 1998, una sentencia de la Corte Constitucional estableció que no podría aplicarse más la figura de sustracción a las áreas de manejo especial. En su lugar, se admitió el realinderamiento, figura utilizada por la Resolución 463 de 2005 de la CAR y el MMA, para excluir 973 has. de la Reserva. Esta fue demandada en el 2005 por una acción popular cuyo fallo, pronunciado por el Tribunal Administrativo de Cundinamarca en el 2006, fue impugnado en dieciséis ocasiones hasta alcanzar el Consejo de Estado. El fallo final del 2014 fue esperado por más de siete años y, desde entonces, ha generado nuevos conflictos, perpetuado otros y complejizándolo sin detener su dinámica.

Son evidentes, a pesar que desde la Declaración de la Reserva se han formulado numerosos instrumentos, normas, planes, regulaciones, etc. para evitar su deterioro o prevenir la formación de conflictos de uso, las dramáticas transformaciones e impactos que ha sufrido (tabla 1). En particular las generadas por la urbanización en el $40 \%$ del área que la franja sustrajo, siendo la pregunta del millón qué pasará con el $60 \%$ restante que no ha sido urbanizada. La lenta reglamentación del fallo final y las pocas decisiones tomadas han probado contribuir poco a la transformación del conflicto. Incluso, parece elevar su intratabilidad si se tienen en cuenta las protestas continuas en pro y contra de la construcción de los proyectos que obtuvieron licencias irregulares que, dicho sea de paso, fueron legalizadas por el Consejo de Estado bajo el estatus de "derechos adquiridos" y "conformidad administrativa". El fallo, desconociendo la función social y ecológica de la propiedad, 1) protegió los derechos de los propietarios, 2) amparó las licencias obtenidas irregularmente y los actos de corrupción que la acción popular solicitaba castigar, 3 ) mantuvo los mecanis- territarias 36

129 
Tabla 1. Ocupación de la franja Res 463 de 2005

\begin{tabular}{|c|c|c|c|}
\hline Ocupación de la Franja & Cantidad & Área (has.) & Porcentaje \% \\
\hline \multicolumn{4}{|c|}{ Incorporaciones } \\
\hline $\begin{array}{l}\text { Predios con actos administrativos de } \\
\text { incorporación }\end{array}$ & 22 & 84 & 8,63 \\
\hline Predios sin licencias vigentes & 8 & 0 & 0 \\
\hline $\begin{array}{l}\text { Predios con licencias de urbanismo o } \\
\text { construcción vigentes }\end{array}$ & 14 & 84 & 8,63 \\
\hline \multicolumn{4}{|c|}{ Desarrollos } \\
\hline Desarrollos de origen informal & 59 & 344,4 & 35,4 \\
\hline Desarrollos legalizados & 36 & 144,53 & 14,85 \\
\hline Desarrollos sin legalizar (San Isidro) & 5 & 162,96 & 16,75 \\
\hline Otros Desarrollos sin legalizar & 18 & 37 & 3,8 \\
\hline \multicolumn{4}{|c|}{ Canteras } \\
\hline Predios con Actividades Mineras & 23 & 32 & 3,29 \\
\hline Canteras en superficie & 11 & 32 & 3,29 \\
\hline Puntos de extracción & 12 & 0 & 0 \\
\hline \multicolumn{4}{|c|}{ Otros } \\
\hline Total Otros & 14 & 97 & 9,97 \\
\hline Malla vial arterial & & 85 & 8,74 \\
\hline Áreas de Actividad Dotacional & 14 & 9 & 0,92 \\
\hline $\begin{array}{l}\text { Áreas ocupadas por infraestructuras de } \\
\text { servicios (Vías y redes) }\end{array}$ & & 3 & 0,31 \\
\hline Total área ocupada & & 557,49 & $57,3 \%$ \\
\hline
\end{tabular}

Fuente: Archivo acción popular, Consejo de Estado, 2013. Anexos probatorios 2014.

mos jurídicos a pesar de su ambigüedad y, por último, 4) no tomó ninguna decisión importante dirigida a atacar una de las

territarias 36 principales causas del conflicto: la falta de claridad de responsabilidades, funciones y competencias, así como no previno su futura formación o por lo menos propendió por la revisión o eliminación de normas redundantes o contradictorias.

\section{Reflexiones finales}

Las dinámicas de gestión del suelo y de la población de la ciudad y sus interrelaciones con las estrategias y prácticas puestas en marcha por los distintos actores involucrados frente al conflicto desde antes y después de la Declaración en 1976 de la Reserva, han constituido un Habitus que ha complejizado la intratabilidad del conflicto. Las estructuras y dispositivos de poder de carácter institucional y cultural que propician la emergencia de los rasgos de intratabilidad, se resisten al cambio por lo cual el conflicto es persistente, recurrente y evade los intentos de transformación. Estos expresan elementos de violencia estructural y simbólica (la pobreza y el rotulo de anormalidad evidente por el uso de rótulos como ilegal, clandestino, o sub normal).

Desde la perspectiva estructural, el acelerado crecimiento de la ciudad ha sido resultado de su condición de receptora permanente de población migrante y desposeída, ya sea como consecuencia de desplazamientos asociados a iniciativas dirigidas al crecimiento económico y las estrategias de desarrollo puestas en marcha por el Estado para articularse al orden económico poscolonial o por causa de la violencia intestina armada y el desplazamiento forzado resultante. La especulación en las ciudades colombianas y en Bogotá 
con la tierra rural vecina y su "conversión" en suelo urbanizable produce burbujas inmobiliarias, relacionadas a nivel macro con fenómenos como el narcotráfico, el lavado de divisas, la inversión y especulación de capitales sobrantes de origen lícito. La enfermedad holandesa generada por el exceso circulante en la economía es resultado, además, de la llegada de grandes capitales provenientes de las exportaciones legales (café, esmeraldas, oro, banano, flores, hidrocarburos, remesas, etc.) o ilegales (dineros de la corrupción, coca, tráfico de especies, de personas, etc.).

La declaración de la Reserva, por ejemplo, fue en su momento una decisión de conservación unilateral llevada a cabo sin ningún tipo de consulta o participación de los actores afectados, y menos aún de coordinación institucional horizontal (distrito y sus secretarías) o vertical (Distrito, CAR, MMA) y esto es un determinante en los fracasos recurrentes de manejo del conflicto. Las prácticas y estrategias puestas en marcha por los actores involucrados para que prevalezca el interés particular sobre el colectivo pueden ser trazadas, cronológica y empíricamente, en palabras de Bourdieu (2000) bajo la forma de regularidades asociadas a las prácticas de planeación, ordenamiento y gestión del suelo de ciudad y de la población que han sido socialmente estructuradas, produciendo sistemas de disposiciones duraderos, estructuras predispuestas a funcionar configurando e intrincando los numerosos rasgos de intratabilidad en la contradicción. Este Habitus ha sido determinante en la construcción de relaciones de poder problemáticas. En la intratabilidad subyacen como causas principales las relaciones de poder (simbólico, institucional y material - inequitativa distribución de costos y beneficios, segregación, inequidad y pobreza, necesidades insatisfechas-) que se resisten a la trasformación o a crear nuevas oportunidades para dar paso al Cambio Social.

Desde la perspectiva cultural ha sido recurrente la importación y aclimatación, muchas veces fallida, de saberes foráneos. Las prácticas institucionales se han adscrito incondicionalmente a discursos hegemónicos como el Urbanismo, la Conservación o el neoliberalismo, con la creación de numerosos mecanismos de seguridad, jurídicos y de policía con lógicas a veces ambiguas, otras contradictorias o no del todo coherentes lo cual ha magnificado rasgos como la segregación, necesidades insatisfechas, los fracasos de la gestión, dilapidación de recursos y la resultante depredación de los recursos naturales, irónicamente bajo la excusa y discursos de la modernidad o la conservación. La puesta en marcha de las medidas de Ajuste en el marco de la racionalidad de actuación neoliberal se han facilitado mediante la figura de las curadurías, la privatización de la vivienda de interés social y el bienestar (salud, educación, etc.) y la desregulación laboral elevando la precariedad. Adicionalmente, ha contribuido mediante instrumentos económicos, como las compensaciones y pagos para legalizar construcciones suntuarias, a incorporar a la Reserva a los circuitos mercantiles, creando nuevas esferas de territarias 36 
influencia para el mercado, ampliando su capacidad de transformación e integración de territorios, personas y recursos, más allá de las fronteras de los Estados Nacionales. Muchas de las normas y regulaciones expedidas en el tiempo bajo paradigmas y marcos de referencia distintos (Preservación, Reserva Forestal o Desarrollo Sostenible) propician la ambigüedad y han dado lugar a contradicciones que superponen o ignoran competencias y funciones de las entidades encargadas de la gestión de los recursos naturales en al menos tres niveles; local, regional y nacional. De modo que, lejos de prevenir o transformar los conflictos, contribuyen a ahondar y complejizar cualquier intento de resolución, propiciando su permanencia y recurrencia. A través del tiempo estos ingredientes y dinámicas se han complejizado y magnificado por cuenta del extenso número de normas, actores involucrados y dimensiones que abarca la contradicción y las prácticas y estrategias institucionales fallidas de control, planeación, normalización, conservación, saneamiento, legalización, provisión de vivienda, servicios básicos, etc.

Existe un Habitus y prácticas arraigadas y recurrentes en lo que se refiere al papel de lo jurídico y lo legal en la legitimación de las intervenciones: el mantenimiento de la creencia de que la realidad social y los conflictos se pueden solucionar mediante la promulgación continúa de decretos, normas y leyes. La constante formulación de normas de gestión ha dado lugar a un intrincado laberinto normativo ambiguo e incoherente que es aprovechado por los grupos de mayor poder para, mediante distintas estrategias legales, imponer sus intereses y evadir el cumplimiento de las leyes. Mientras, los barrios autoproducidos esperan por décadas la legalización, y consecuentes inversiones de normalización, para luego ser gentrificados. Las licencias irregulares para estratos altos en la Reserva son símbolo de las ambigüedades que permiten el ejercicio de una cierta discrecionalidad en la toma de decisiones de incorporación al perímetro urbano lo que, a su vez, propicia la corrupción e impunidad.

En lo que se refiere al papel del Estado y sus prácticas, estas adoptan múltiples formas para configurar los rasgos de permanencia del conflicto: las permanentes reestructuraciones, fracaso constante de las repuestas a las protestas o a los intentos de trasformación y reticencia de las estructuras a cambiar o transformarse. En lo que respecta a la orientación de las intervenciones, se han presentado continuos bandazos de política urbana, la adopción de distintos enfoques para regular el suelo y el abandono constante de planes y proyectos. Esto se relaciona con una permanente dependencia dependencia y adscripción incondicional a los discursos y saberes de moda en el Norte, cuyas lógicas son pensadas para contextos diferentes, con poca coherencia y rigurosidad. Las intervenciones urbanísticas (planes viales) que desde el enfoque procedimental se han puesto en marcha han promovido la especulación con el suelo urbano, así como han permitido beneficiar a los grupos con 
mayor poder, alimentar la corrupción y la captura de las instituciones. A pesar de los repetidos intentos de regulación y disciplinamiento las dinámicas constructivas la urbe ha tenido, desde sus inicios y hasta la actualidad, una larga y recurrente historia de autoproducción del hábitat ligada a trayectorias históricas, económicas, políticas y culturales arraigadas ligadas a la pobreza y la migración y articulada al clientelismo y los tierreros. Es claro que el dispositivo clientelista ha permitido la transferencia permanentemente de los costos de las tensiones institucionales, inoperancia, corrupción e ineficiencia al colectivo por la vía impuestos y endeudamiento. Los costos en todas las dimensiones (programas de Mejoramiento y Regularización), de una parte, subsidian y elevan los beneficios obtenidos por la maquinaria de la urbanización informal al tiempo que, de otra, aceitan la articulación de las poblaciones de los barrios al clientelismo reproduciendo una dinámica perversa cuyos costos económicos pagan los contribuyentes y cuyos costos ecológicos y sociales son transferidos a la ciudad y al colectivo.

Un rasgo determinante de la intratabilidad corresponde precisamente a la lucha por necesidades fundamentales. Las prácticas institucionales han contribuido a la generación de pobreza que, como vimos, ha propiciado la segregación socio espacial, la distribución inequitativa de los costos y beneficios de las intervenciones distritales y la extracción de recursos vía urbanización, clientelismo y gentrificación. Adicionalmente, los pobladores de estos barrios "ilegales" no cuentan con inversión para la satisfacción de sus necesidades básicas. La maraña de regulaciones ha impedido la legalización y acceso a servicios fundamentales, sin atacar las causas: las declaraciones unilaterales de áreas protegidas, la corrupción, tráfico de influencias, la discrecionalidad en la aplicación de normas urbanistas, el loteo ilegal y tácticas y actuaciones de los tierreros-políticos en el Consejo y Senado, entre otras.

\section{Referencias}

Acción popular de Sonia Andrea Ramírez Lamy (Consejo de Estado, 5 de noviembre de 2013). Recuperado de https://www.minminas.gov.co/ documents/10180/23517/36643Sentencia-25023250002005006620305Nov2013.pdf

Acuerdo Distrital 68. Diario Oficial de la República de Colombia, Bogotá, Colombia, 14 de noviembre de 1961.

Acuerdo Distrital 21. Consejo de Bogotá, Bogotá, Colombia, 10 de junio de 1972.

Acuerdo Distrital 22. Consejo de Bogotá, Bogotá, Colombia, 10 de junio de 1972.

Acuerdo CAR 53. Bogotá, Colombia, 10 de noviembre de 1981.

Acuerdo CAR 59. Diario Oficial de la República de Colombia, Bogotá, Colombia, 30 de octubre de 1987.

Alcaldía de Bogotá. (2010). Informe de conservación Internacional del proyecto Quebradas de Chapinero. Bogotá: Autor. territarias 36 
Aprile, J. (1992). La ciudad colombiana: siglo XIX y siglo XX. Bogotá: Fondo de Promoción de la Cultura del Banco Popular.

Arango, C. (1981). Crónicas de la lucha por la vivienda en Colombia. Bogotá: Editorial Colombia Nueva.

Azar, E. (1985). Protracted international conflicts: Ten propositions. International Interactions: Empirical and Theoretical Research in International Relations, 12(1), 59-70. doi: http://dx.doi. org/10.1080/03050628508434647

Azar, E. (1990). The Management of Protracted Social Conflict: Theory and Cases. Michigan: Dartmouth Pub Co.

Azar, E. (1991). The Analysis and Management of Protacted Social Conflicts. En V. Volkan, J. Montville, \& D. Julius (Ed.), The Psychodynamics of International Relationships(Vol. 2) (pp. 93-140). Lexington: Lexington Books.

Bourdieu, P. (1977). Outline of a Theory of Practice (Cambridge Studies in Social and Cultural Anthropology). Cambridge: University of Cambridge.

Bourdieu, P. (2000). Poder, derecho y clases sociales (2 ${ }^{\mathrm{a}} \mathrm{Ed}$.). Bilbao: Desclée de Brouwer.

Brand, P. (2001). La Planeación Urbana y las Ciencias Sociales en Colombia. Revista de Estudios Sociales, (10), 133-141.

Camargo, G. (2001). El proceso histórico y las perspectivas de ordenamiento de los Cerros Orientales de Bogotá DC. Ambiente y desarrollo, (9), 119-136.

territarias 36

Camargo, G. (2002). Análisis ecológico de la dinámica de transformación de los bordes urbanos en Bogotá D.C. (Informe final de investigación). Universidad Piloto de Colombia, Bogotá.

Campo Albán, M. L. (2012). Bogotá en la década de 1970: el piduzob como referente teórico de la planeación acción (Tesis Doctoral). Universidad Nacional de Colombia, Bogotá. Recuperada de http://www.bdigital.unal.edu. co/9955/1/393240.2012.pdf

Castro Gómez, S. (2005). La hybris del punto cero: ciencia, raza e ilustración en la Nueva Granada. Bogotá: Editorial Pontificia Universidad Javeriana.

Castro Gómez, S. (2009). Tejidos Oníricos Movilidad, capitalismo y biopolitica en Bogotá (1910-1930). Bogotá: Editorial Pontificia Universidad Javeriana. Recuperado de https://sinismos.files. wordpress.com/2012/06/51810398castro-gomez-santiago-tejidos-oniricos. pdf

Chaparro V., J., Mendoza, D. M. \& Pulido, B. M. (1997). Un siglo habitando los cerros: Vidas y milagros de vecinos en el Cerro del Cable. Bogotá: Alcaldía Local y Junta Administradora Local de Chapinero- Corporación Comunitaria Raíces- Instituto Distrital de Cultura y Turismo.

Colón, L. C. (2005). El saneamiento del Paseo Bolívar y la vivienda obrera en Bogotá. Revista Urbanismos, (2), 104115.

Contraloría Distrital. (2004). Informe final de auditoria gubernamental con enfoque integral. Plan de Auditoria Distrital 2003-2004. Bogotá: Autor. 
Cuevas, O. \& Vargas, A. (2004). Reurbanización en la microcuenca de la quebrada La Chorrera, Nororiente de Bogotá (1960-2004). Bogotá: Universidad Nacional.

Dávila, A. (2002). La metamorfosis del sistema político Colombiano: ¿Clientelismo de mercado o nueva forma de intermediación? En F. Gutiérrez (Comp.), Degradación o Cambio. Evolución del sistema politico Colombiano (pp. 319356). Bogotá: Editorial Norma.

Decreto $\mathrm{N}^{\circ}$ 3640. Diario Oficial de la República de Colombia, Bogotá, Colombia, 21 de enero de 1955.

Decreto $N^{\circ} 2811$. Diario Oficial de la República de Colombia, Bogotá, Colombia, 18 de diciembre de 1974.

Decreto $N^{\circ} 877$. Diario Oficial de la República de Colombia, Bogotá, Colombia, 10 de mayo de 1976.

Decreto $N^{\circ}$ 622. Diario Oficial de la República de Colombia, Bogotá, Colombia, 16 de marzo de 1977.

Decreto Ley $\mathrm{N}^{\circ}$ 100. Diario Oficial de la República de Colombia, Bogotá, Colombia, 20 de febrero de 1980.

Díaz, W., Gómez, J., González, J., Secretaría Distrital de Planeación \& Universidad Nacional de Colombia. (2007). Segregación socioeconómica en el espacio urbano de Bogotá. Bogotá: Secretaria Distrital de Planeación.

Díaz Mosquera, C. A. (20 de abril de 2009). Procesos de Urbanización [Entrada de blog]. Recuperado de http://carlosdiazmosquera.blogspot.com.co/
EAAB. (2003). El agua en la historia de Bogotá. Bogotá: Villegas Editores.

Flórez, C. \& Romero, O. (2010). La demografía de Colombia en el siglo XIX. En A. Meisel \& M. T. Ramírez (Eds.), Economia colombiana del siglo XIX (pp. 375-418). Bogotá: Fondo de Cultura Económica.

Georges, V. (1976). Traslados residenciales de los inmigrantes de bajos ingresos: el caso de Bogotá, Colombia. En R. Cardona (Ed.), Distribución espacial de la población (pp. 141-169). Bogotá: Corporación Centro Regional de la Población.

Hataya, N. (2010). La ilusión de la participación comunitaria. Lucha y negociación en los barrios irregulares de Bogotá 19922003. Bogotá: Universidad Externado. Hernández, O. \& Vargas, E. (2009). La función social y ecológica de la propiedad en los cerros orientales de Bogotá: el caso del barrio San Luis del Cabo. (Tesis de pregrado). Recuperada de la base de datos de la Universidad de Los Andes https://biblioteca.uniandes.edu.co/ visor_de_tesis/web/?SessionID $=\mathrm{LI} \mathrm{R}$ lc2lzXzEyMDEwX3ByaW1lc19zZW1 lc3RyZS8zOS5wZGY\%3D

Jaramillo, B. (1947). Pepe sierra: el método de un campesino millonario. Medellín: Bedout.

Londoño, R. \& Saldarriaga, A. (1994). La ciudad de Dios en Bogotá. Barrio Villa Javier. Bogotá: Fundación Social.

Lewicky, R. J., Gray, B. \& Elliott, M. (2003). Making sense of intractable environmen- territarias 36

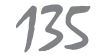


tal conflicts: concepts and cases. Washington: Island Press.

Martínez, S. (noviembre de 2007). Sintesis de la problemática de las áreas desarrolladas informalmente. Bogotá: Secretaría Distrital de Planeación. Recuperado de http://es.slideshare.net/smmtocan/ retrospectiva-asentamientos-informalesbogota

Martínez, S. (2010). Mohanes, candilejas y santos: perspectivas de la comunidad indígena muisca de Bosa sobre la contaminación del río Tunjuelito en Bogotá. En M. Serje (Ed.), Desarrollo $y$ Conflicto: territorios, recursos y paisajes en la historia oculta de proyectos y politicas (pp. 159-186). Bogotá: Universidad de los Andes.

Mejía Pavony, G. (2000). Los años del cambio: historia urbana de Bogotá, 1820-1910. Bogotá: Editorial Pontificia Universidad Javeriana.

Mejía Pavony, G. (2012). La ciudad de los conquistadores 1536-1604. Bogotá: Editorial Pontificia Universidad Javeriana.

Méndez, F., Gómez, O., Girón, S., Mateus, J., Mosquera, J., Filigrana, P., ... \& Gulloso, L. (2006). Evaluación del impacto del relleno sanitario Doña Juana en la salud de grupos poblacionales en su área de influencia. [Versión Adobe Digital Editions] Recuperado de http://www. cerrarelbotadero.org/inicio/archivos/ EstudioEpidemiologicoRSDJ.pdf

Molano Camargo, F. (jun-dic, 2007). El paro cívico nacional del 14 de septiembre de

\section{territarias 36}

dad. Revista Ciudad Paz-Ando, 3(2), 111-142.

Murad, R. (2003). Estudio sobre la distribución espacial de la población en Colombia. Bogotá: CEPAL.

Ocampo, G. (2003). Urbanización por invasión. Conflicto urbano, clientelismo y resistencia en Córdoba (Colombia). Revista Colombiana de Antropología, 39, 237-271. Recuperado de http:// www.icanh.gov.co/recursos_user/ RCA_Vol_39/v39a08.pdf

Osorio, J. (2007). El río Tunjuelo en la historia de Bogotá, 1900-1990. Bogotá: Secretaria Distrital de Cultura.

Osorio, J. (2010). Conflicto y Desarrollo. En M. Serje (Ed.), Desarrollo y Conflicto: territorios, recursos y paisajes en la historia oculta de proyectos y politicas (pp. 1-28). Bogotá: Universidad de los Andes.

Ospina, C. (oct - dic, 2010). Reseña de “Tejidos oníricos: movilidad, capitalismo y biopolítica en Bogotá (1910-1930)". Revista Nómadas, (33), 262-264.

Palacio, G. (2008). Historia ambiental de Bogotá y la Sabana, 1850-2005. Bogotá: Universidad Nacional de Colombia.

Perry, S. (1994). Las Luchas Campesinas en Colombia. En A. Machado (Comp.), El Agro y la Cuestión Social (pp. 229261). Bogotá: Tercer Mundo Editores. Preciado, J., Leal, R. \& Castañeda, C. (2005). Historia ambiental de Bogotá, siglo XX: elementos históricos para la formulación del medio ambiente urbano. Bogotá: Universidad Distrital Francisco José de Caldas. 
Puente Burgos, C. (2005). Urbanización clandestina: la discusión teórica. (Documento de trabajo). Bogotá: Editorial Pontificia Universidad Javeriana.

Quijano, A. (oct-dic, 1993). América Latina en la economía mundial. Problemas del Desarrollo, 24(95), 43-59.

Ramírez Ríos, J. (sept-dic 2011). Urban Planning in Colombia between the 1960s and 80s: Discourses, Consultants, and Academic. Revista de Estudios Sociales, (40), 115-125.

Ramírez Soto, J. (1983). La vivienda popular hoy en Colombia. Bogotá: CINEP.

Rico, G. (jul-dic, 2010). Discurso y poder en la construcción del hábitat el caso los cerros surorientales de Bogotá. Bitácora Urbano Territorial, 2(19), 123-137.

Rodríguez Gómez, J., \& Villegas, B. (2003). El agua en la historia de Bogotá: 15381937. Bogotá: Villegas Editores.

Salamanca, B. \& Camargo, G. (2000). Protocolo distrital de restauración ecológica. Bogotá: Departamento Técnico Administrativo del Medio Ambiente

Saldarriaga, J. \& Manuel, D. J. (jul-dic, 2012). El "giro experimental" de los saberes sobre lo social en Colombia, 1840-1903. Revista Eletrônica Da ANPHLAC, (13), 251-311.

Sánchez Steiner, L. (jul-dic, 2008). Éxodos rurales y urbanización en Colombia Perspectiva histórica y aproximaciones teóricas. Bitácora Urbano Territorial, 13, 57-72.
Serna, A., \& Gómez Navas, D. (2012). El Carmelo: historia de una antigua barriada bogotana en la cuenca del río Arzobispo (1900-1934). Historia Critica, (47), 161-186. doi: http://dx.doi. org/10.7440/histcrit47.2012.09

Suárez, J., \& Castillo, R. (2005). Estudio Reubicación in-situ del barrio La Esperanza (UPZ 89 San Isidro Patios). Bogotá: Universidad de los Andes.

Torres Tovar, C. A. (2007). Ciudad informal colombiana. Grupo de investigación "Procesos Urbanos en Hábitat, Vivienda e Informalidad". Bitácora Urbano Territorial, 11(1), 53-93. Recuperado de http://www.redalyc.org/articulo. oa? id=74811106

Torres Tovar, C. A., \& Castillo, M. (2005). Caracterización de la Ciudad, el Hábitat y la Vivienda Informal en la Colombia de los años 90. Bogotá: Universidad Nacional.

Torres, L. A. (1993). La ciudad en la sombra. Barrios y luchas populares en Bogotá 1950-1977. Bogotá: CINEP.

Zambrano, F., Casteblanco, C., Sánchez, L., Hoyos, J., Ruíz, M. \& Benninghoff, F. (2000). Comunidades y territorios: reconstrucción historia de Usaquén. Bogotá: Impresol Ediciones

Zamudio, R. (ene-jun, 2010). Urbanismo pirata: tácticas y estrategias en asentamientos informales. Revista Traza, l(1), 197-208. territarias 36

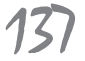


